\title{
Quantitative Detection of Cathepsin B Activity in Neutral pH Buffers Using Gold Microelectrode Arrays: Toward Direct Multiplex Analyses of Extracellular Proteases in Human Serum
}

\author{
Yang Song a , Jestin Gage Wright a, Morgan J. Anderson b, Sabari Rajendran a, Zhaoyang Ren a, \\ Duy H. Hua a , Jessica E. Koehne ${ }^{\text {b }}$, M. Meyyappan ${ }^{\text {b }}$, and Jun Li ${ }^{\text {a,* }}$ \\ a Department of Chemistry, Kansas State University, Manhattan, KS 66502, United States \\ b NASA Ames Research Center, Moffett Field, CA 94035, United States \\ * Corresponding Author: Phone: +1 785532 0955; fax: +1 785532 6666; E-mail: junli@ksu.edu \\ (J. Li)
}




\section{Table of Contents}

\section{Materials and Instruments}

\section{Au MEA Fabrication}

a. Figure S1. Au MEA layout on a 4" $\mathrm{SiO}_{2} / \mathrm{Si}$ wafer and structure of $\mathrm{Au} \mathrm{MEA}$

\section{ELISA Measurements}

a. Figure S2. Schematic illustration of the procedure for a sandwich-type Enzyme-Linked Immunosorbent Assay (ELISA)

b. Figure S3. The OD readings of ELISA measurements of diluted HS in 0.5X PB

c. Figure S4. A 64-well plate design used for ELISA measurements at varied rhCB concentrations

\section{Michaelis-Menten Model for Electrochemical Data Analysis}

a. Figure S5. CV curves of various Au electrodes

b. Figure S6. Raw and baseline-subtracted ACV curves of various Au electrodes

\section{Kinetic Proteolysis Measurements on Au MEA in Different Buffers}
a. Figure S7. Kinetic proteolysis curve in $25 \mathrm{mM}$ MES buffer $(\mathrm{pH}=5.0)$
b. Figure S8. Kinetic proteolysis curve in $0.2 \mathrm{X}, 0.5 \mathrm{X}$ and $1 \mathrm{X}$ PBS $(\mathrm{pH}=7.4)$
c. Figure S9. Kinetic proteolysis curve in $0.5 \mathrm{X} \mathrm{PB}(\mathrm{pH}=7.4)$

\section{Electrochemical Kinetic Proteolysis in 5\% Human Serum Samples}

a. Figure S10. Kinetic proteolysis curve of 5\% pooled human serum in $0.5 \mathrm{X}$ PB

b. Figure S11. Kinetic proteolysis curve of 5\% pooled human serum in $0.5 \mathrm{X}$ PB spiked with $1.0 \mathrm{nM}$ non-activated cathepsin $\mathrm{B}(0.4 \mathrm{nM}$ natural active form)

c. Figure S12. Kinetic proteolysis curve of 5\% pooled human serum in $0.5 \mathrm{X}$ PB spiked with $1.0 \mathrm{nM}$ activated cathepsin $\mathrm{B}$ 


\section{Materials and Instruments}

$N$-Fluorenylmethyloxycarbonyl (Fmoc) protected amino acid, 1-[bis(dimethylamino)methylene]1H-1,2,3-triazolo[4,5-b]pyridinium 3-oxide hexafluorophosphate (HATU), amino acid attached 2chlorotrityl resins, and 2-(1H-benzortiazol-1-yl)-1,1,3,3-tetramethyluronium hexafluorophosphate (HBTU) were bought from Chem-Impex International, Inc. (Wood Dale, IL) and AAPPTEC LLC (Louisville, KY). N-Hydroxysulfosuccinimide (Sulfo-NHS), 6-mercapto-1-hexanol, and 6mercapto-1-hexanoic, and 1-ethyl-3-(3-dimethylaminopropyl)carbodiimide (EDC) were purchased from Sigma-Aldrich (St. Louis, MO). Sodium phosphate dibasic heptahydrate $\left(\mathrm{Na}_{2} \mathrm{HPO}_{4} \cdot 7 \mathrm{H}_{2} \mathrm{O}\right)$, sodium phosphate monobasic monohydrate $\left(\mathrm{NaH}_{2} \mathrm{PO}_{4} \cdot \mathrm{H}_{2} \mathrm{O}\right)$, dithiothreitol, and 2-(4-morpholino)ethanesulfonic acid (MES) were purchased from Fisher Scientific (Hampton, $\mathrm{NH}$ ). The $1 \mathrm{X}$ phosphate buffer (PB) was prepared as $7.17 \mathrm{mM}$ potassium phosphate dibasic anhydrous and $4.63 \mathrm{mM}$ potassium phosphate monobasic $(\mathrm{pH}=7.4$, adjusted using potassium hydroxide) purchased from Fisher Scientific (Fair Lawn, NJ) in deionized water. This was modified from the standard phosphate buffer saline (PBS) by removing other salts to lower the ionic strength. The $0.5 \mathrm{X}$ PB was prepared by 2 -fold dilution of $1 \mathrm{X}$ PB with deionized water to further lowering the ionic strength. Carrier-free recombinant human cathepsin B (rhCB) ( $60 \% 37$ kDa proenzyme, 40\% $29 \mathrm{kDa}$ mature enzyme), cathepsin B specific fluorogenic peptide substrate, human total cathepsin B DuoSet ELISA kit, and DuoSet ancillary reagent kit 2 were obtained from R\&D Systems Inc. (Minneapolis, MN). Solutions of $1 \%$ bovine serum albumin (BSA) in $0.5 X$ PB were prepared as $10 \mathrm{mg} / \mathrm{mL}$ from solid bovine serum albumin purchased from Tocris Bioscience (Bristol, UK). Cathepsin B solutions were activated in $25 \mathrm{mM}$ MES buffer containing $5 \mathrm{mM}$ DTT for $15 \mathrm{~min}$ to activate the proenzyme. The ferrocene $(\mathrm{Fc})$ labeled peptide substrate $\mathrm{H}_{2} \mathrm{~N}-\left(\mathrm{CH}_{2}\right)_{4}{ }^{-}$ CO-Pro-Leu-Ala-Phe-Val-Ala-NH- $\mathrm{CH}_{2}-\mathrm{Fc}$ (peptide-Fc) was designed according to the literature 
reported sequences and synthesized using a solid-phase microwave peptide synthesizer CEM Discover (Matthews, NC) in D. H. Hua's laboratory. The synthetic procedure was described in a previously published article (referred as H-15). ${ }^{1} \mathrm{~A}$ "pooled human serum off the clot" (catalog no. ISER10ML, Innovative Research, Novi, Michigan) was used to validate the detection. Such human serum (HS) sample was whole blood derived by allowing the blood to clot and then processed into serum via centrifugation. The supernatant serum solution was frozen immediately after processing.

\section{Fabrication of Au MEA}

The 4" $\mathrm{Si}(100)$ wafer was first oxidized in gaseous $\mathrm{H}_{2} \mathrm{O}$ at $1100{ }^{\circ} \mathrm{C}$ for $45 \mathrm{~min}$ to form a $550 \mathrm{~nm} \mathrm{SiO}{ }_{2}$ layer on the surface. Then, the wafers were coated with $\mathrm{Ti}, \mathrm{Au}$, and $\mathrm{Ti}$ of thickness $20 \mathrm{~nm}, 100 \mathrm{~nm}$, and $20 \mathrm{~nm}$ sequentially by using electron beam evaporation (Innotec ES26C, Battle Ground, WA). The wafers were then spin-coated with an automated spin-coating track (SVG 8400, San Jose, CA) with $1.0 \mu \mathrm{m}$ SPR3612 positive photoresist (Rohm and Haas Electronic Materials, Marlborough, MA) and exposed on a mask aligner (Karl Suss MA-1, Garching, Germany) with an exposure dose of $80 \mathrm{~mJ} / \mathrm{cm}^{2}$ (exposure time $=5.3 \mathrm{~s}$ ) through a chrome photomask (FrontRange Photomask, Lake Havasu City, AZ). After developed with an automated developing track (SVG 8600, San Jose, CA), a photoresist electrode MEA pattern was formed on the wafer. The exposed Ti top layer was then etched with $2 \%$ aqueous HF solution, the underneath Au layer was removed with Transene TFA Au, and again with 2\% HF to remove the bottom layer of Ti. The MEA pattern was retained because of the photoresist, which was stripped off after etching. A 1- $-\mu \mathrm{m}$ thick layer of $\mathrm{SiO}_{2}$ was deposited over the entire wafer by plasma-enhanced chemical vapor deposition (PE-CVD, Plasma-Therm Shuttle-lock SLR-730-PECVD, St. Petersburg, FL) with $250 \mathrm{sccm} \mathrm{5 \%} \mathrm{SiH}_{4} / \mathrm{He}, 800 \mathrm{sccm} \mathrm{He}$ and $1700 \mathrm{sccm} \mathrm{N}_{2} \mathrm{O}$ at $350{ }^{\circ} \mathrm{C}, 1100$ 
mTorr and $200 \mathrm{~W}$ for $15 \mathrm{~min}$. Next, the second photolithography step with the same recipe was processed on the wafer again to expose the contact pad and microelectrode while covering the remaining areas protected by photoresist. The exposed $\mathrm{SiO}_{2}$ was etched with $\mathrm{CHF}_{3}$ plasma $(2 \mathrm{sccm}$ $\mathrm{O}_{2}$ and $45 \mathrm{sccm} \mathrm{CHF}_{3}$ at $5.0 \mathrm{mTorr}$ for $8 \mathrm{~min}$ ) using a reactive ion etcher (RIE, Plasma-Therm Versaline LL-ICP, St. Petersburg, FL), and then the top layer of Ti was etched with $2 \%$ aqueous HF to expose the Au surface. Finally, the wafers were coated with a 5.0- $\mu$ m layer of SPR3612 as a protective layer. A wafer saw (DISCO DAD3240, Tokyo, Japan) was used to dice the wafer into individual chips. Prior to use, the chips were sonicated in acetone for $10 \mathrm{~min}$, followed by rinsing with methanol and isopropanol to remove the protective layer.

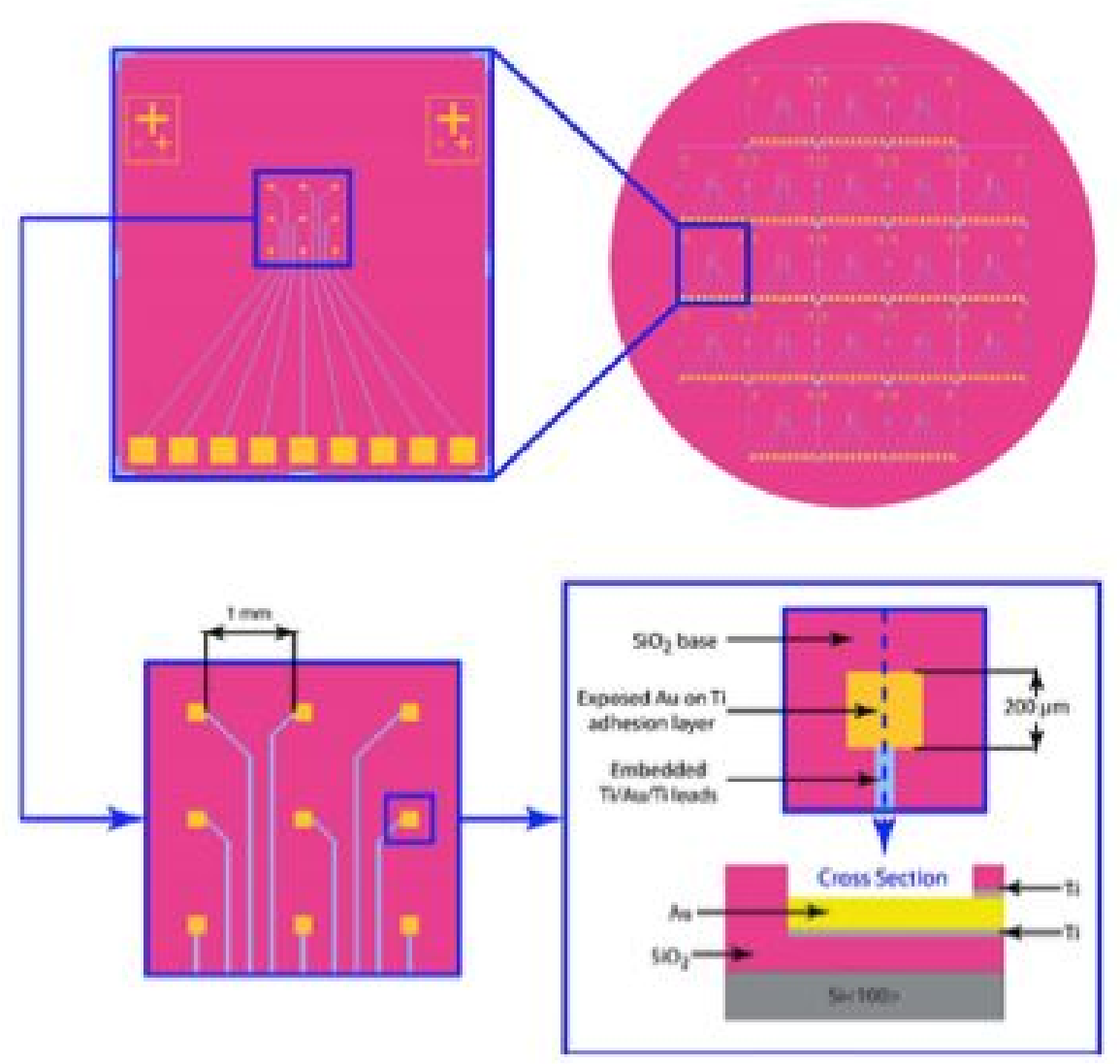

Figure S1. Schematic Illustration of the gold microelectrode array (MEA) chip layout on a 4" $\mathrm{SiO}_{2} / \mathrm{Si}$ wafer and the designed structure of the Au MEA with the edge and contact lines encapsulated by the surrounding $\mathrm{SiO}_{2}$ film. The exposed microelectrodes and the contact pads are shown in gold color while the contact lines between them are in grey color to indicate that they are covered by a thin layer of $\mathrm{SiO}_{2}$. 


\section{ELISA Measurements}

Cathepsin B concentrations were determined using enzyme-linked immunosorbent assay (ELISA) kits from R\&D Systems. A schematic illustration of the ELISA procedure used is shown in Figure S2. First, the wells were coated with the primary antibody by incubation with $100 \mu \mathrm{L}$ of PBS containing $4.00 \mu \mathrm{g} / \mathrm{mL}$ mouse anti-human cathepsin B antibodies at room temperature for 810 hours (Figure S2A). Each well was washed three times with $0.05 \%$ Tween 20 in a standard PBS solution and dried by tapping them against a firm surface padded with sterile laboratory tissue. The plates were then passivated by incubation with $300 \mu \mathrm{L}$ 1\% BSA in PBS buffer per well at room temperature for 1 hour (Figure S2B) and washed with 0.05\% Tween 20 in the PBS buffer. Samples with rhCB were prepared via serial dilution from $1.0 \mathrm{nM}$ stock solutions in $0.5 \mathrm{X}$ PB buffer containing 1\% BSA according to the plate design shown in Figure S3A. Another series were prepared in $0.5 \mathrm{X}$ PB buffer containing 1\% BSA after adding $2.5 \% \mathrm{HS}$. When applicable, solutions of $36 \mathrm{nM} \mathrm{rhCB}$ and 90\% HS were activated by incubation in 2-(4-morpholino) ethanesulfonic acid (MES) buffer containing $5 \mathrm{mM}$ dithiothreitol (DTT) at room temperature for 15 minutes before diluting into proper rhCB concentration for ELISA measurements. Varied concentrations of HS were also prepared via serial dilution with $1 \% \mathrm{BSA}$ in $0.5 \mathrm{X} \mathrm{PB}$ for generating a calibration curve. In some experiments, the HS was activated in MES and DTT same as above and then diluted to desired concentrations.

ELISA measurements were performed in quadruplicate on the 96-well plates. To the quadruplicate wells, $100 \mu \mathrm{L}$ of each sample was added, incubated at room temperature for 2 hours (Figure S2C), and washed with $0.05 \%$ Tween 20 in the PBS buffer. Following this, the plates were further incubated with $100 \mu \mathrm{L}$ of $50.0 \mathrm{ng} / \mathrm{mL}$ biotinylated goat anti-human cathepsin B antibodies 
in $1 \%$ BSA in PBS at room temperature for 2 hours (Figure S2D) and washed with $0.05 \%$ Tween 20 in the PBS buffer. The plates were then incubated with $100 \mu \mathrm{L}$ of $20 \mathrm{ng} / \mathrm{mL}$ streptavidinconjugated horseradish peroxidase prepared in $1 \%$ BSA in PBS at room temperature for 20 minutes in the absence of light (Figure S2E) and washed with $0.05 \%$ Tween 20 in the PBS buffer. Finally, the plates were incubated with $100 \mu \mathrm{L}$ of a 1:1 (volume ratio) solution of hydrogen peroxide and 3,3',5,5'-tetramethylbenzidine (TMB) at room temperature for 20 minutes in the absence of light, which provided signal amplification via the catalytic oxidation of TMB. The reaction was stopped by addition of $50 \mu \mathrm{L} 1.0 \mathrm{M}$ sulfuric acid per well to convert it into a yellow product (Figure S2F). Once developed, the OD of the wells was read immediately at $450 \mathrm{~nm}$ wavelength to obtain the calibration curve (Figure S3). Figure S4A shows the typical 64-well plate design used for the ELISA measurement. The cathepsin B ELISA experiment in this study was diluted in $1 \%$ BSA in $0.5 \mathrm{X}$ PB buffer (blue) or $2.5 \%$ human serum with $1 \%$ BSA in $0.5 \mathrm{X}$ PB buffer (orange). An image of a developed plate following the above procedure is shown in Figure S4B. 


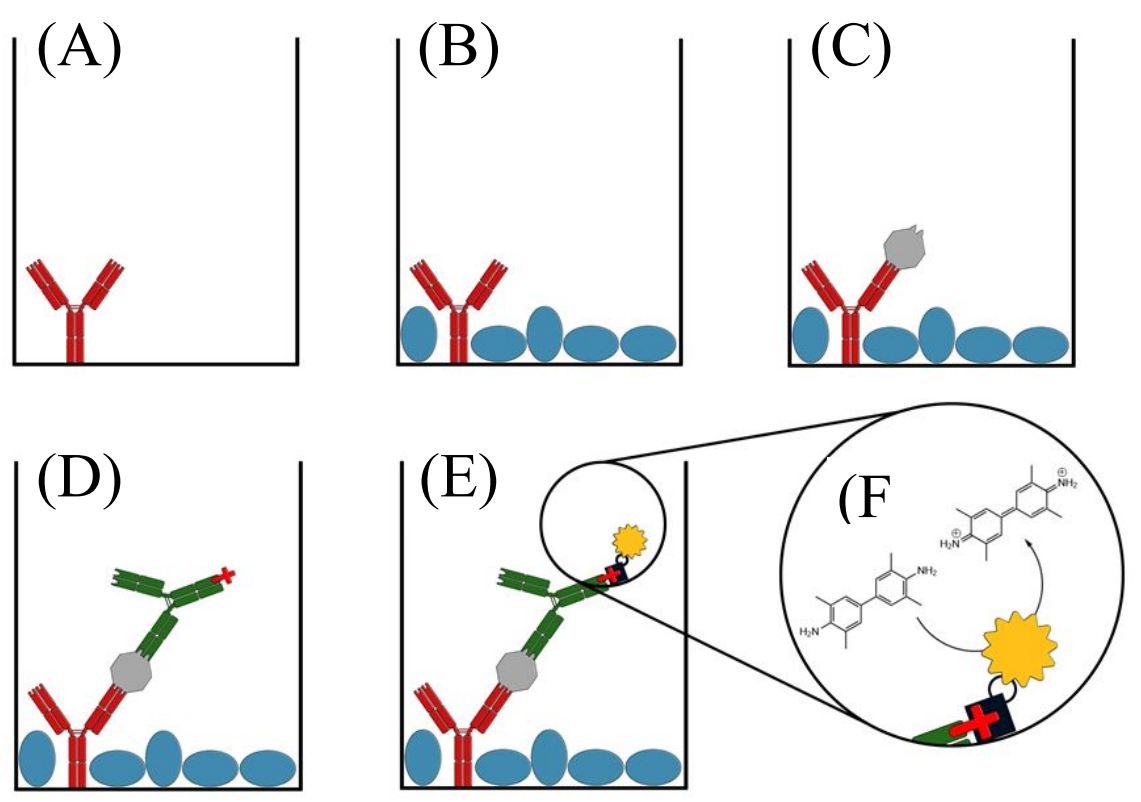

Figure S2. Schematic illustration of the procedure for a sandwich-type ELISA for detecting cathepsin B. (A) The primary antibody adsorbs to the polystyrene well. (B) The remaining surface area of the well is passivated with bovine serum albumin. (C) Cathepsin B binds to the immobilized primary antibody. (D) The secondary, biotin-labeled antibody binds to immobilized cathepsin B. (E) Streptavidin-conjugated horseradish peroxidase attaches to the biotin label. (F) Catalytic oxidation of the substrate to a colored product. The well is washed thoroughly with a surfactant solution $(0.05 \%$ Tween 20 in the PBS buffer) between the steps in each panel.

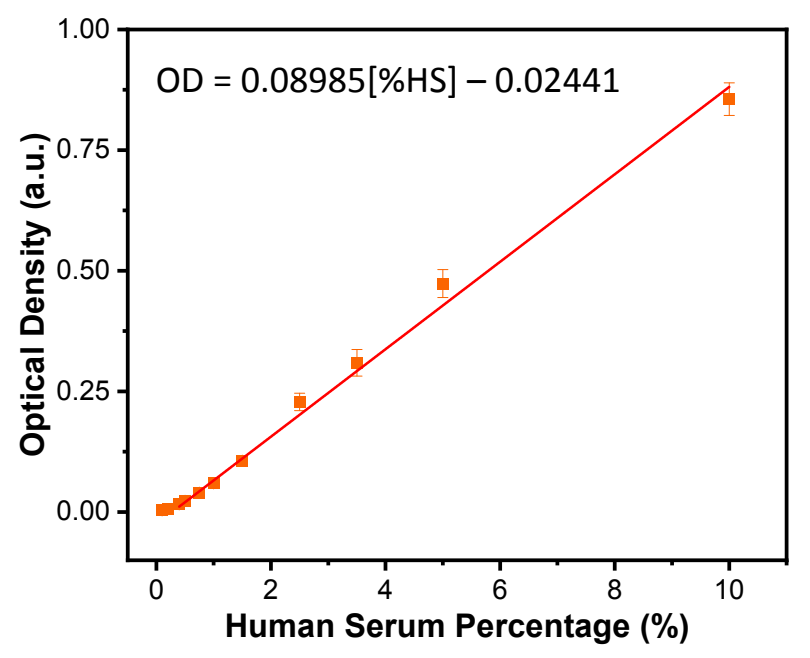

Figure S3. The OD readings in ELISA measurements of a series of HS diluted with 0.5X PB containing $1 \%$ BSA. Even though all data points can be reasonably fitted with a linear line, the point above $5 \%$ HS starts to drop below the line by other points. 
(A)

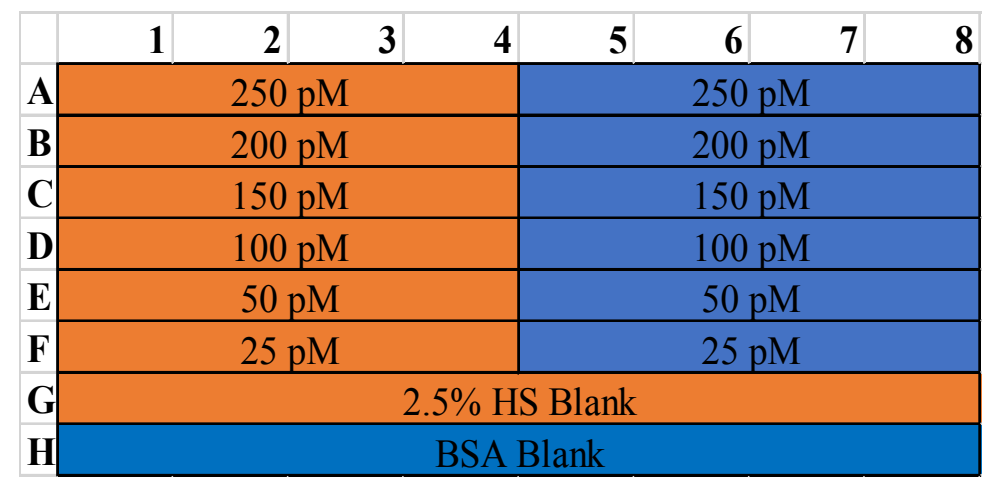

(B)

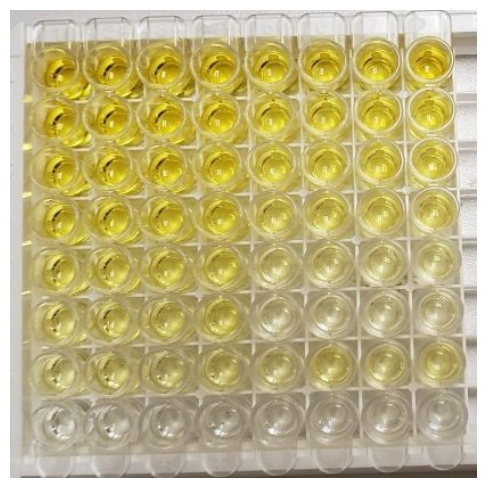

Figure S4. (A) A typical 64-well plate design used for ELISA measurements of a series of various concentrations of recombinant human cathepsin B diluted in 1\% BSA in $0.5 \mathrm{X}$ PB buffer (blue) or $2.5 \% \mathrm{HS}$ added to $1 \% \mathrm{BSA}$ in $0.5 \mathrm{X} \mathrm{PB}$ (orange). (B) A typical optical image of the wells after signal amplification and conversion $(0<\mathrm{OD}<1.6)$.

\section{Michaelis-Menten Model for Electrochemical Data Analysis}

Our previous studies have described the exponential kinetics of the proteolysis reaction by the Michaelis-Menten model for the heterogeneous enzymatic reaction: ${ }^{1,2}$

$$
E+S_{S} \stackrel{k_{1}}{\stackrel{k_{-1}}{\rightrightarrows}} E S_{S} \stackrel{k_{c a t}}{\Rightarrow} E+P_{S}+P
$$

where $\mathrm{E}$ is the active enzyme, $\mathrm{S}_{\mathrm{s}}$ is the surface-functionalized peptide-Fc substrate, $\mathrm{ES}_{\mathrm{s}}$ is the enzyme-substrate complex on the electrode surface, $\mathrm{P}_{\mathrm{s}}$ is the peptide fragment remaining on the surface after proteolysis cleavage, and $\mathrm{P}$ is the released peptide fragment containing $\mathrm{Fc}$, and $k_{l}, k_{-}$ I, and $k_{c a t}$ are the rate constant of related reactions. Based on the steady-state assumption, the reaction rate can be described as

$$
v=-\frac{d \Gamma_{s_{s}}}{d t}=\frac{k_{c a t}}{\mathrm{~K}_{\mathrm{M}}+[E]_{0}}[E]_{0} \Gamma_{S_{s}},
$$


where $\Gamma s_{s}$ is the surface concentration of peptide-Fc substrate, $K_{M}$ is the Michaelis-Menten constant $\mathrm{K}_{\mathrm{M}}=\left(k_{c a t}+\mathrm{k}_{-1}\right) / \mathrm{k}_{1}$ and $[\mathrm{E}]_{0}$ is the active enzyme concentration. The cyclic voltammograms (CVs) in Figure S5 show that the peptide-Fc functionalized Au electrode presents a pair of well-defined redox waves around $-0.15 \mathrm{~V}$ (vs. MSE) which is attributed to $\mathrm{Fc} / \mathrm{Fc}^{+}$reaction. These peaks disappeared after cleaving the peptide-Fc substrate by proteolysis. The charge under the oxidation peak of the CV (i.e. the integrated peak area divided by the scan rate) indicates the surface density of the peptide-Fc substrate, which is $\Gamma S_{S}=3.1 \mathrm{pmol} / \mathrm{cm}^{2}$. This corresponds to an average nearest-neighbor distance of $7.9 \mathrm{~nm}$, allowing easy access to the peptide-Fc by the protease. The weak signal can be amplified by using ACV. As shown in Figure S6, the ACV uses an AC voltage wave with a frequency $(300 \mathrm{~Hz})$ and voltage amplitude $(100 \mathrm{mV})$ on top of a DC ramp from $-0.45 \mathrm{~V}$ to $0.20 \mathrm{~V}$ (vs. MSE (saturated $\mathrm{K}_{2} \mathrm{SO}_{4}$ )) at $10 \mathrm{mV} / \mathrm{s}$ scan rate, which generates an ACV peak at the same potential $(-0.15 \mathrm{~V})$ as in $\mathrm{CV}$. The capacitive baseline can be subtracted from the raw ACV curves to extract the faradaic ACV peak current $i_{p}$, which decreases versus the proteolysis time. Since $i_{p}$ is proportional to the Fc-moiety density, the reaction rate can also be written as:

$$
-\frac{d\left({ }^{i} p / i_{p_{0}}\right)}{d t}=\frac{k_{c a t}}{\mathrm{~K}_{\mathrm{M}}+\left[E_{0}\right]}[E]_{0}\left(\frac{i_{p}}{i_{p_{0}}}\right) .
$$

If we assume $\mathrm{K}_{\mathrm{M}} \gg[E]_{0}$, we can derive

$$
-\frac{d\left({ }^{i} p / i_{p_{0}}\right)}{d t} \approx \frac{k_{c a t}}{\mathrm{~K}_{\mathrm{M}}}[E]_{0}\left(\frac{i_{p}}{i_{p_{0}}}\right) .
$$

After integrating equation (5), we have 


$$
\frac{i_{p}}{i_{p_{0}}}=\exp \left(-\frac{k_{c a t}}{K_{M}}[E]_{0} t\right)=\exp [-t / \tau]
$$

Finally, we have the relationship between the exponential decay time constant $\tau$ and the fundamental protease properties as

$$
\frac{1}{\tau}=\left(\frac{k_{c a t}}{K_{M}}\right)[E]_{0}
$$
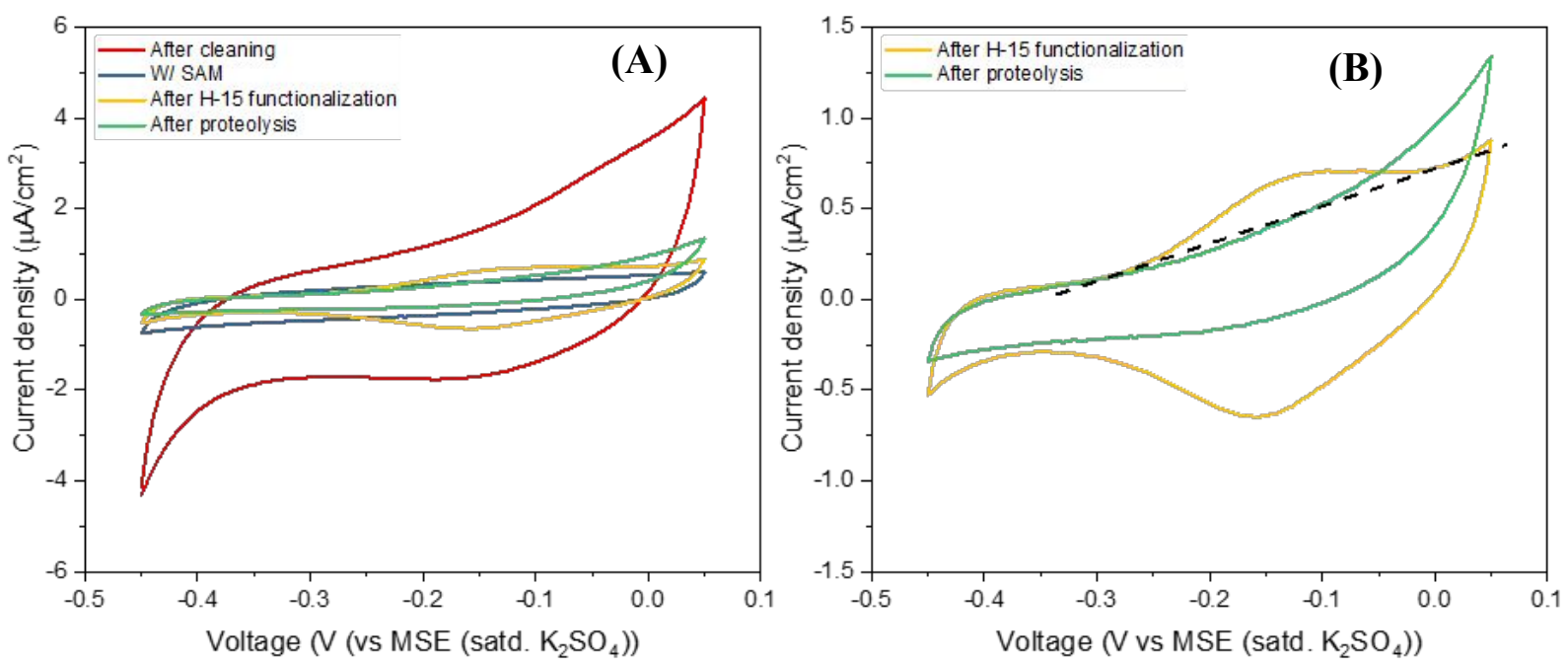

Figure S5. (A) Cyclic voltammograms of a clean Au electrode, after forming a self-assembled monolayer (SAM) of thiol linkers, further functionalized with $\mathrm{H}-15$ peptide-Fc and after proteolysis in 5\% human serum (non-activated). All measurements were done at $100 \mathrm{mV} / \mathrm{s}$ scan rate in $0.5 \mathrm{X}$ PB. (B) Enlarged view of the cyclic voltammogram of $\mathrm{H}-15$ peptide-Fc functionalized $\mathrm{SAM} / \mathrm{Au}$ before and after proteolysis by $5 \%$ human serum in $0.5 \mathrm{X} \mathrm{PB}$.
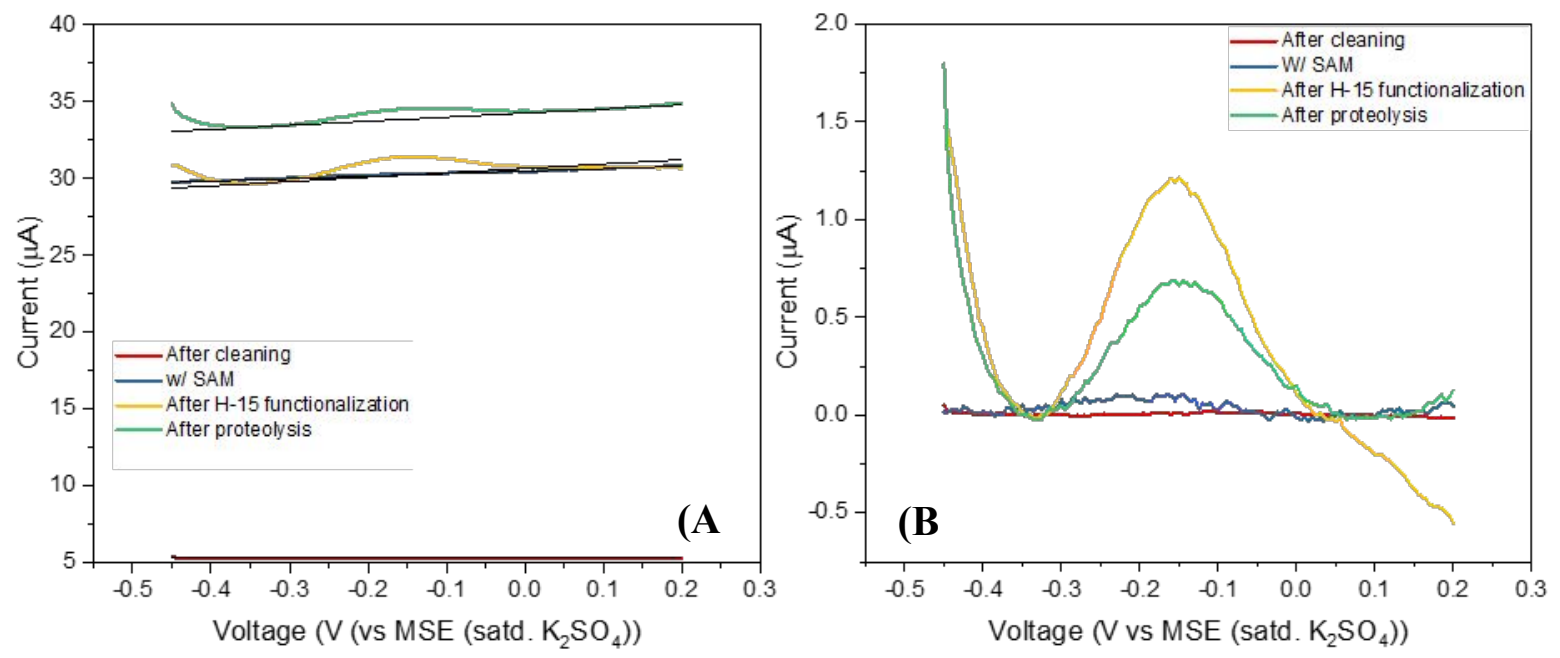

Figure S6. (A) The raw and (B) the background-subtracted AC voltammetry curves of a clean Au electrode, after forming a self-assembled monolayer (SAM) of thiol linkers, further functionalized 
with $\mathrm{H}-15$ peptide-Fc and after proteolysis in 5\% human serum (non-activated). All measurements were done with $100 \mathrm{mV}$ AC voltage amplitude at $300 \mathrm{~Hz}$ AC frequency superimposed on a DC ramp from $-0.45 \mathrm{~V}$ to $0.20 \mathrm{~V}$ (vs MSE (saturated $\mathrm{K}_{2} \mathrm{SO}_{4}$ )) at $10 \mathrm{mV} / \mathrm{s}$ scan rate.

\section{Kinetic Proteolysis Measurements using Au MEA in Different Buffers}
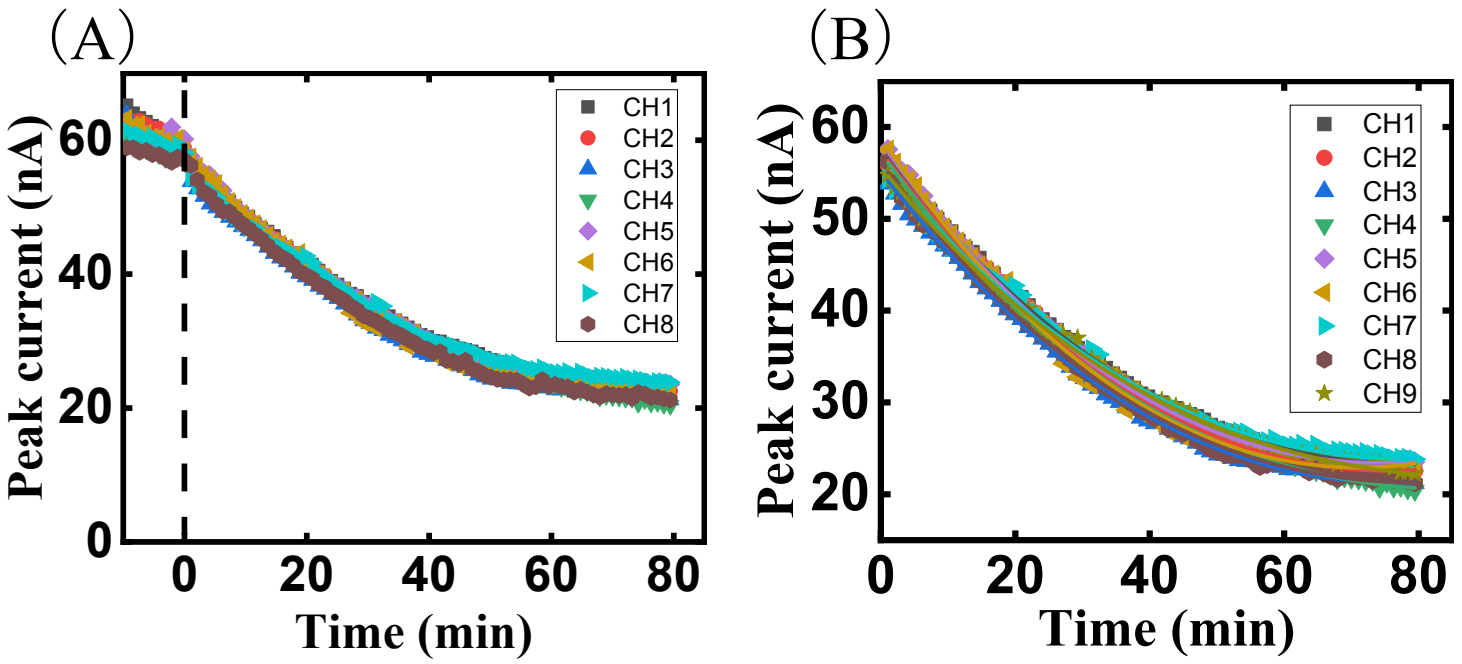

Figure S7. (A) Kinetic proteolysis curves of an Au MEA modified with peptide-Fc substrate, $\mathrm{H}_{2} \mathrm{~N}$ $\left(\mathrm{CH}_{2}\right)_{4}-\mathrm{CO}-$ Pro-Leu-Ala-Phe-Val-Ala-NH- $\mathrm{CH}_{2}-\mathrm{Fc}$, by $1.0 \mathrm{nM}$ cathepsin B in the $25 \mathrm{mM}$ MES buffer $(\mathrm{pH}=5.0)$. (B) The fitting curves to the extracted proteolysis portion.
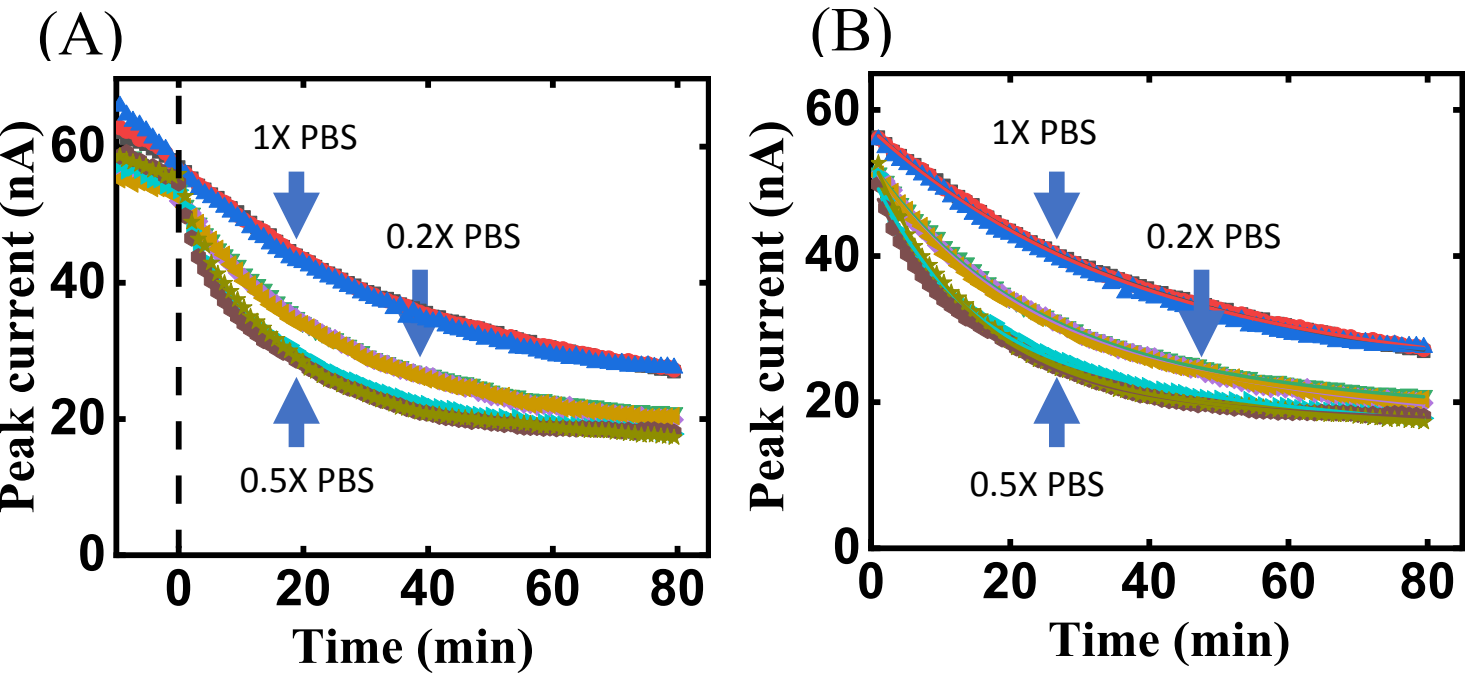

Figure S8. (A) Kinetic proteolysis curves of an Au MEA modified with the peptide-Fc substrate, $\mathrm{H}_{2} \mathrm{~N}-\left(\mathrm{CH}_{2}\right)_{4}-\mathrm{CO}-$ Pro-Leu-Ala-Phe-Val-Ala-NH- $\mathrm{CH}_{2}-\mathrm{Fc}$, by $1.0 \mathrm{nM}$ cathepsin $\mathrm{B}$ in $1 \mathrm{X}, 0.5 \mathrm{X}$ and 
$0.2 X$ PBS buffer $(\mathrm{pH}=7.4)$. (B) The fitting curves to the extracted proteolysis portion. For clarity, only three proteolysis curves are shown at each buffer concentration.
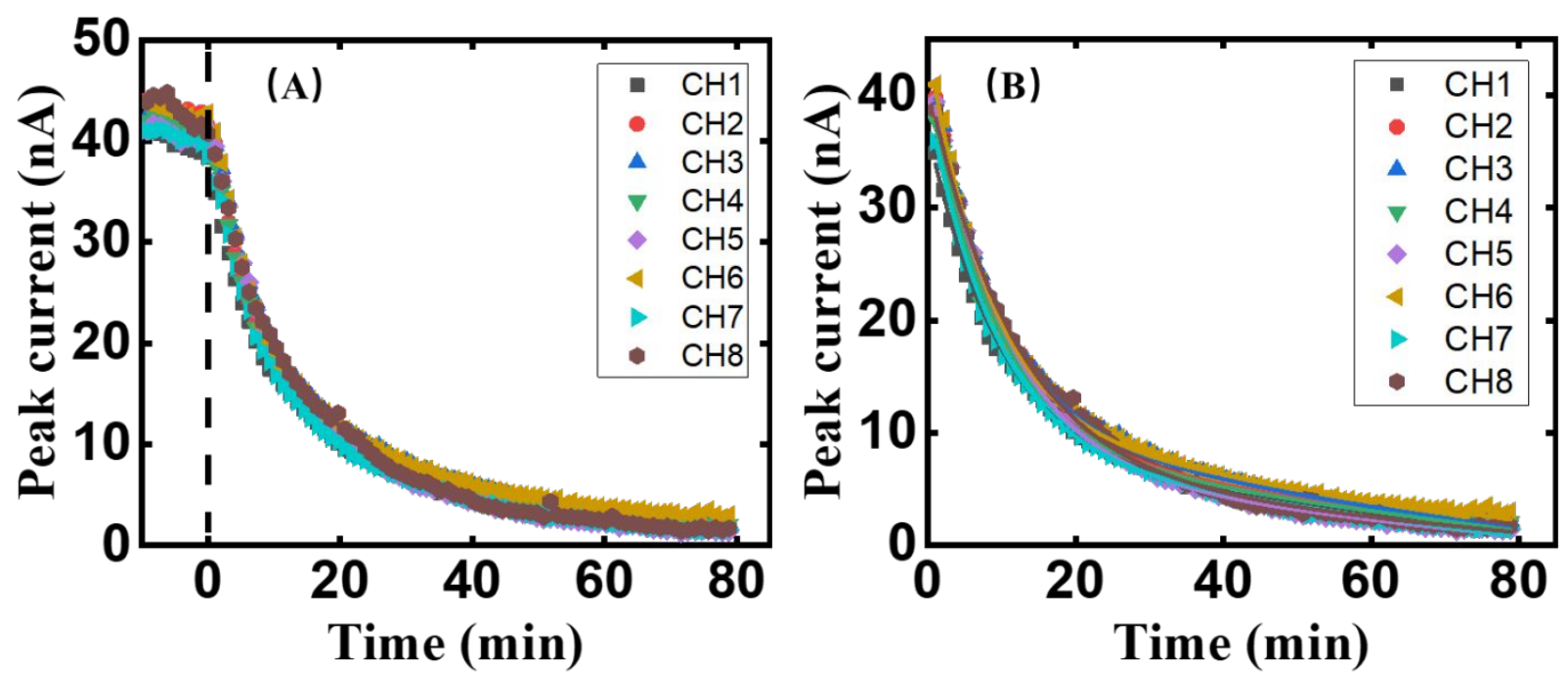

Figure S9. (A) Kinetic proteolysis curves of an Au MEA modified with peptide-Fc substrate, $\mathrm{H}_{2} \mathrm{~N}$ $\left(\mathrm{CH}_{2}\right)_{4}$-CO-Pro-Leu-Ala-Phe-Val-Ala-NH-CH$-\mathrm{Cc}$, by $1.0 \mathrm{nM}$ cathepsin B in $0.5 \mathrm{X}$ PB buffer $(\mathrm{pH}$ $=7.4)$. (B) The fitting curves to the extracted proteolysis portion.

6. Electrochemical Kinetic Proteolysis in 5\% Human Serum Samples
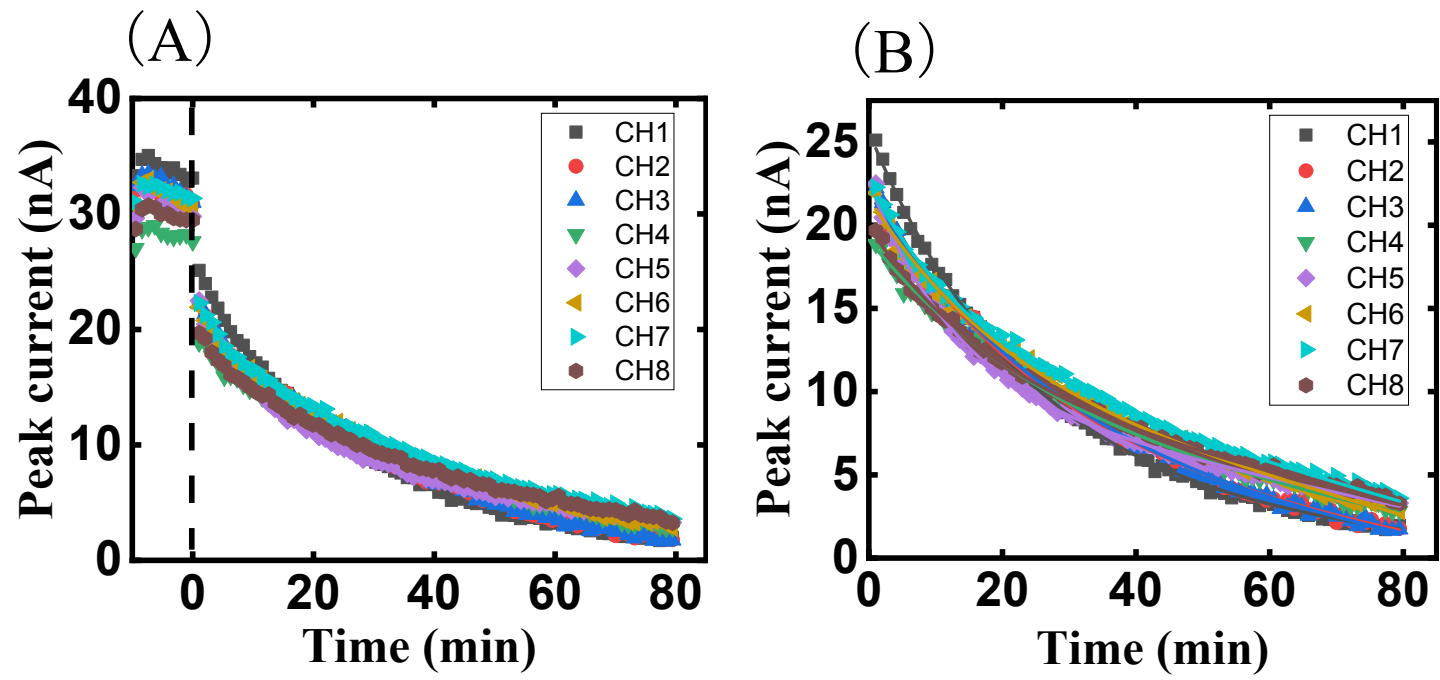

Figure S10. (A) Kinetic proteolysis curves of peptide-Fc modified Au MEA by 5\% HS in $0.5 \mathrm{X}$ $\mathrm{PB}$ buffer $(\mathrm{pH}=7.4)$. (B) The extracted proteolysis curves and corresponding fitting lines. 

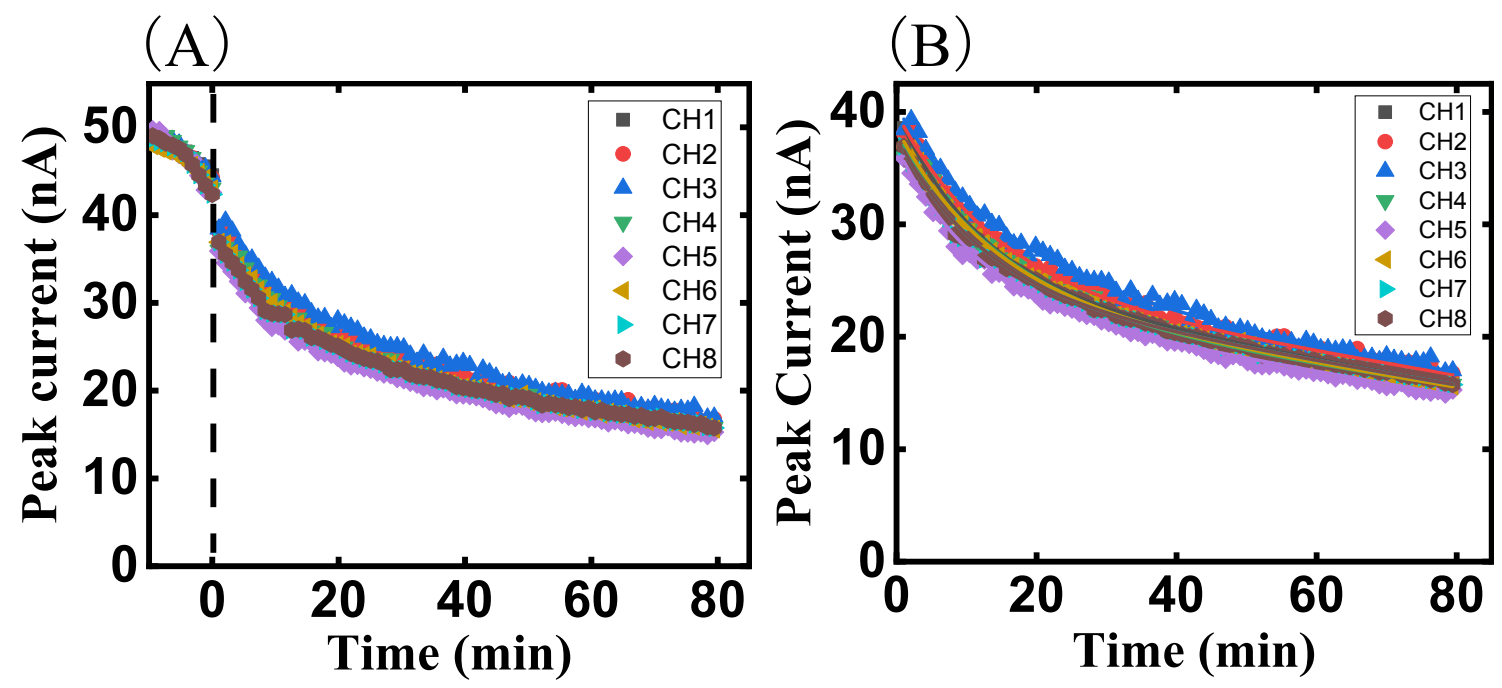

Figure S11. (A) Kinetic proteolysis curves of peptide-Fc modified Au MEA by 5\% HS in $0.5 \mathrm{X}$ PB buffer ( $\mathrm{pH}=7.4)$ spiked with $1.0 \mathrm{nM}$ cathepsin $\mathrm{B}$ (containing $0.40 \mathrm{nM}$ active form). (B) The extracted proteolysis curves and corresponding fitting lines.
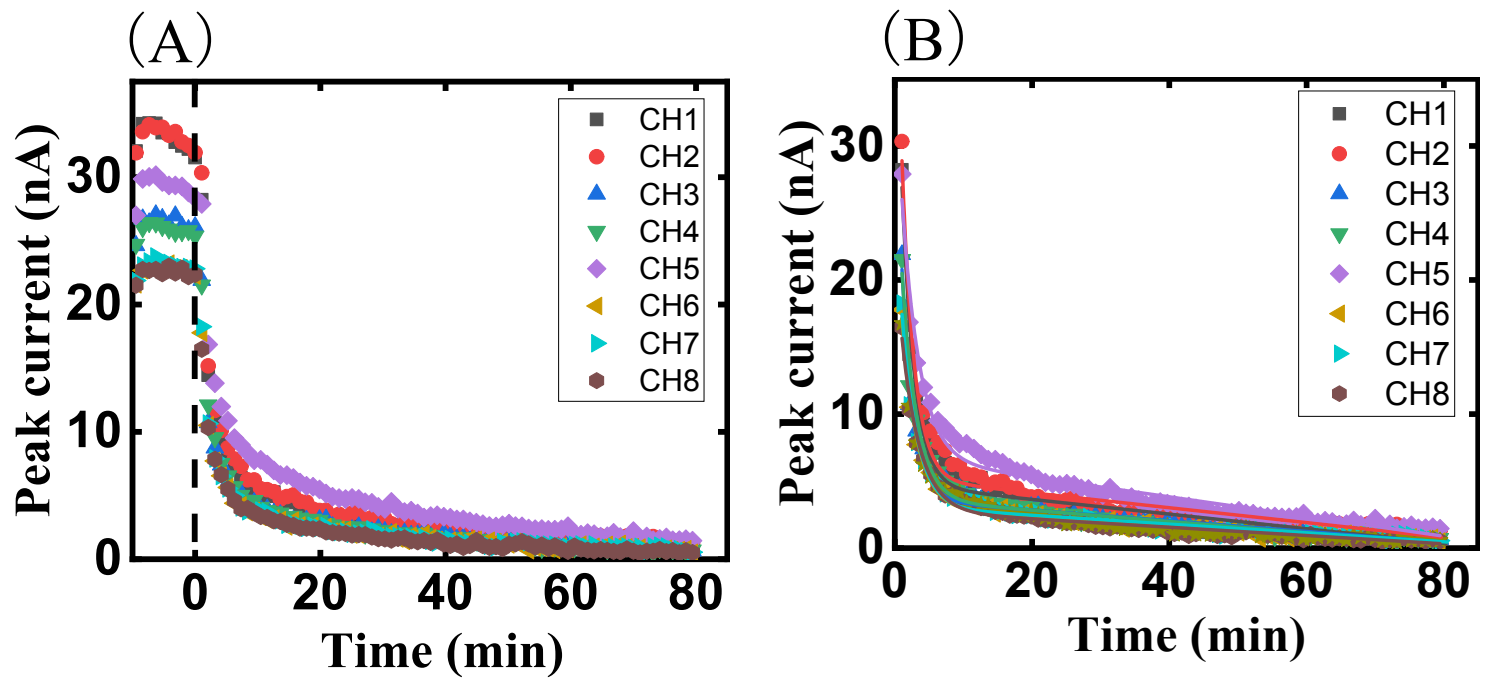

Figure S12. (A) Kinetic proteolysis curves of peptide-Fc modified Au MEA by 5\% HS in $0.5 \mathrm{X}$ PB buffer ( $\mathrm{pH}=7.4$ ) spiked with $1.0 \mathrm{nM}$ active cathepsin $\mathrm{B}$. (B) The extracted proteolysis curves and corresponding fitting lines.

\section{References:}

1. Anderson, M. J.; Song, Y.; Fan, H.; Wright, J. G.; Ren, Z.; Hua, D. H.; Koehne, J. E.; 
Meyyappan, M.; Li, J., Simultaneous, multiplex quantification of protease activities using a gold microelectrode array. Biosensors and Bioelectronics 2020, 165, 112330 (9 pages).

DOI: $10.1016 /$ j.bios.2020.112330

2. Song, Y.; Fan, H. F.; Anderson, M. J.; Wright, J. G.; Hua, D. H.; Koehne, J.; Meyyappan, M.; Li, J., Electrochemical Activity Assay for Protease Analysis Using Carbon Nanofiber Nanoelectrode Arrays. Analytical Chemistry 2019, 91 (6), 3971-3979. 